\title{
Ekoeleştirel ve Doğakültürel Bir Müzikoloji Yaklaşımı Olarak Ekomüzikoloji
}

\section{Ecomusicology as an Ecocritical and Naturecultural Approach to Musicology}

\section{Ulaş ÖZDEMIR ${ }^{1}$ (D)}

'Dr. Öğr. Üyesi, İstanbul Üniversitesi Devlet Konservatuarı, Müzikoloji Bölümü, İstanbul, Türkiye

ORCID: U.Ö. 0000-0003-4528-517X

\section{Sorumlu yazar/Corresponding author: Ulaş Özdemir \\ İstanbul Üniversitesi Devlet Konservatuarı, Müzikoloji Bölümü, Rıhtım Caddesi, No:1 34710, Kadıköy İstanbul, Türkiye \\ E-posta/E-mail: ulasozdemir@istanbul.edu.tr}

Bașvuru/Submitted: 31.08 .2018

Kabul/Accepted: 05.11.2019

Online Yayın/Published Online: 13.11.2019

Atıf/Citation: Ozdemir, U. (2019). Ekoeleștirel ve doğakültürel bir müzikoloji yaklaşımı olarak ekomüzikoloji. Konservatoryum -

Conservatorium. Advanced Online Publication. https://doi.org/10.26650/CONS2019-0012 öz

2. Dünya Savaşı sonrasında akademik alana hızla yayılan eleştirel düşünce, sosyal bilimler ve kültürel çalışmalar altında pek çok yeni çalışma alanının ortaya çıkmasını sağlamıştır. 1980'li yıllarda yaygın olarak gelişen edebiyat merkezli ekoeleştiri ve yine benzer dönemlerde gelişen eleştirel veya yeni müzikoloji çalışmaları, eleştirel yaklaşımlarıyla mevcut paradigmaları sarsmıştır. Ekoeleştiri düşüncesi ile müzikoloji disiplinini bir araya getiren ekomüzikoloji alanı ise müzik ve kültür arasındaki ilişkiye doğayı da katarak, çevre/doğa konusuna ses ve müzik açısından bakan yeni bir yaklaşım ortaya çıkarmıştır. Disiplinlerarası bir perspektifle çevre/doğa bağlamında birçok konuyla ilgilenen ekomüzikoloji çalışmaları, bilimsel ve aktivist bir çabadır. İnsan-doğa ilișkisini sorgulayan ve günümüzdeki çevre krizleri ile sürdürülebilirlik sorunlarına müzikolojinin sınırlarını genişleterek yanıtlar bulmaya çalışan ekomüzikoloji, 2000'li yıllardan itibaren tüm dünyada hızla gelişen bir alan olmuştur. Bu makalede, ekoeleştirel ve doğakültürel bir müzikoloji yaklaşımı olarak ekomüzikolojinin ortaya çıkışı, bu alanda yapılan çalışmalar ile alanla ilgili kavramsal ve yöntemsel tartışmalar konuyla ilgili temel kaynaklar üzerinden incelenmiştir. Bu makalenin, gelecekte Türkiye'de ekomüzikoloji alanında yapılacak araştırmalara yol gösterici olması hedeflenmiștir.

Anahtar Kelimeler: Ekomüzikoloji, Müzikoloji, Ekoeleştiri

\section{ABSTRACT}

After World War II, the rapid spread of critical theory led to the emergence of many new fields of study under the social sciences and cultural studies. The literary centered ecocriticism, which was developed in the 1980s, and the critical or new musicology studies that developed in similar periods, influenced the existing paradigms with their critical approaches. The field of ecomusicology, which brings together the idea of ecocriticism with the discipline of musicology, has brought a new approach to the environment/nature issues in terms of sound and music, adding nature to the relationship between music and culture. Ecomusicology studies dealing with many issues in the context of environment/nature from an interdisciplinary perspective is both a scientific and an activist effort. By questioning the humannature relationship and trying to find answers to today's environmental crises and sustainability problems by expanding the boundaries of musicology, ecomusicology has been a rapidly developing field since the 2000s. In this article, the emergence of ecomusicology as an ecocritical and naturecultural musicology approach, as well as conceptual and methodological discussions concerning this field are examined through the main sources. This article is intended to be a guide to future research in the field of ecomusicology in Turkey.

Keywords: Ecomusicology, Musicology, Ecocriticism 


\section{EXTENDED ABSTRACT}

The relationship between human and nature is critically re-considered today. Particularly in Western culture, the way of thinking in which human and nature are constructed as opposites has been examined and criticized in depth through critical studies. After World War II, both the development of critical thinking in the academic field and the emergence of environmental crises all over the world have increased the debate on environmental/ nature awareness. From the late 1960s onwards, critical approaches began to multiply in different fields of science, and over time, they became more prominent with the discussions of postmodernism and poststructuralism. In parallel with the development of the idea of ecocriticism in the field of literature, critical or new musicology studies have influenced the existing paradigms in the field of musicology, and the question of what music is in this context has begun to be handled from a very broad perspective.

In this period in which the human-nature relationship was reconsidered, academic studies on the one hand and activist activities for the environment on the other hand increased, and scientific, artistic or activist studies were carried out in many subjects from the protection of natural life to the environmental crisis. Sustainability of ecosystems has been one of the most important topics among these studies.

Studies that emerged as "critical musicology" in the UK or "new musicology" in the United States and developed under the influence of different critical theories have the approach that musicology should be critically considered as a science. Today, influencing the "old" musicological paradigms, the so-called new or critical musicology studies have also come into contact with different sub-branches of ethnomusicology and have created a broad framework of music sciences that can be regarded as "new (ethno)musicologies". Thus, musicology has become an "intertextual field". One such practice is ecomusicology, nurtured by both new (ethno)musicological approaches and ecocritical thinking.

The ecocritical approach in musicology developed in parallel with the spread of environmental concern in physics, natural and social sciences, especially in the 1970s, but it gained value as "ecomusicology" in North American and Scandinavian academic circles in the 2000s. The critical and activist approach of the new musicology studies to the positivist music research influenced ecomusicology. Different conceptual and methodological tools are used in ecomusicology studies that intersect with different fields such 
as sound studies, acoustics, bioacoustics, sociology, anthropology, philosophy, cultural studies, and environmental studies and sciences.

The field of ecomusicology, where ecocritical thinking and musicology come together, has included nature in music and culture studies, and has greatly expanded its field of study, and has enabled the study of all kinds of sounds existing in nature. Ecomusicologists, who are open to other disciplines conceptually and methodically, are interdisciplinary. With their political positions on environment/nature issues, ecomusicologists seeking to respond to ecological crises through music research by developing environmental/ nature awareness both in academia and outside academia, therefore go one step beyond the musicology with the answers they find and become "involved" in environmental/ nature issues. Another important issue on which ecomusicology focuses is the sustainability of music cultures as ecosystems.

Ecomusicology tends to approach and discuss the objects in question from an expanding point of view by critically examining not only what we mean by "nature", but also by "music". In other words, ecomusicology, as an ecocritical and naturecultural musicology approach, is an interdisciplinary field that raises critical questions about the relationship between music, culture, and nature and seeks answers to these questions. Today ecomusicology is a rapidly evolving field as an ecocritical and naturecultural musicology approach with a wide range of study subjects, conceptual world, and methodological tools. In this article, the history and development process of the ecomusicology field is examined in detail with the aim of presenting a perspective for future research in this field in Turkey. 


\section{Giriş}

İnsan ve doğa ilişkisi, antik çağlardan bu yana başta felsefenin, daha sonra hemen hemen tüm bilim dallarının en temel konularından biridir. Çoğunlukla felsefeden diğer disiplinlere devredilen insan-doğa ikiliği, özellikle Batı kültüründe bu iki kavramın birbirine karşıt olarak kurgulanmasından dolayı zamanla eleştirel bir çerçevede ele alınmıştır. Tüm dünyaya yayılan çevresel krizin de etkisiyle, insan merkezli doğa düşüncesi yerine, insanı doğanın bir parçası olarak kabul eden çeşitli eleştirel yaklaşımlar ortaya çıkmış, bunlar bilimsel çalışmaları da derinden etkilemiştir. Doğanın tahribatında insanın rolünü sorgulayan ve insan-doğa ilişkisini yeniden düşünmeyi öneren çalışmaların yaygınlaşmasıyla, ekoloji bilimi diğer disiplinlerle işbirliği yaparak yeni alanlara açılmıştır. Bununla birlikte eleştirel ekolojik çalışmalar, sosyal bilimler ve kültürel çalışmalar içinde pek çok yeni disiplinlerarası araştırma alanı ortaya çıkarmıştır. Ekomüzikoloji de bu alanlardan birisidir. $\mathrm{Bu}$ makalede, giderek tüm dünyaya yayılan ekomüzikoloji yaklaş1m1, kavramsal ve yöntemsel açıdan incelenmektedir.

\section{Ekoloji Düşüncesinin Gelişimi}

Genel olarak insanların doğa üzerindeki etkileri üzerine bir kavram olarak düşünülen ekoloji, aslında canlılar ve çevreleri arasındaki tüm ilişkileri inceleyen bilimin adıdır (Callenbach, 2011, s. 41). Raymond Williams (2012), ekoloji (ecology) kelimesinin etimolojik olarak gelişimini ve bilimsel kullanımını şöyle açıklar:

“Ecology, Alman zoolog Haeckel'den çeviri yoluyla gelen bilimsel kullanımı (aslen oecology) 1870’lere kadar gitse de 20. yüzyılın ortalarından önce İngilizce'de yaygın değildir. Ancak Thoreau'da, görünüşe göre yalıtılmış ve garip denecek ölçüde uygun, 1858 yılına ait bir kullanımı vardır. Sözcük, Yunanca kök sözcük oikos -ev halk1- ile logos'tan -söylem, buradan da dizgesel inceleme- gelen tanıdık logy takısıyla türetilmiştir. (...) Ecology (Haeckel'in ökologie'si) habitat (18. yüzyıldan itibaren karakteristik yaşama yerini anlatan bir isim, "yaşar" anlamındaki Latince fiil biçiminden) anlamını geliştirdi ve de bitkilerle hayvanların birbiriyle ve yaşama alanlarıyla ilişkilerinin incelenmesi biçimini aldı. (...) Environmentalist [çevreci] ve ilişkili sözcükler, 1950’lerden itibaren conservation [çevreyi koruma] ve kirliliğe karşı önlemlere ilişkin kaygıyı ifade etmek üzere yaygınlaştı. Ecology ve ilişkili sözcükler 1960'ların sonundan itibaren bu konumlarını devam ettirip genişleterek environment gruplaşmasının büyük ölçüde yerini aldılar" (s. 133-134). 
Yani ekoloji, organizmalarla (ya da ait oldukları popülasyonlarla) çevreleri arasındaki etkileşimin incelenmesidir (Bates, 2009, s. 89). Doğal ayıklanma mekanizmasıyla işleyen bu süreçte ekolojik etken aslî önem taşır; yani organizmalarla çevreleri arasındaki uygunluk esastır. Her türlü çevreye uyarlanabilen ekosistem kavramı ise popülasyonların çevrelerinden nasıl etkilendiklerini ve onu nasıl etkileyebildiğini betimlemeye olanak sağlar (Bates, 2009, s. 90). Bu sayede, doğada belli bir çevredeki ekosistemi anlamak mümkün olur. Tersinden söyleyecek olursak, her ekosistemin ya da ekolojik sistemlerin "doğa"sı vardır: "Eğer her tekil şey kendi doğasına sahipse, o takdirde doğa herşeyin temel özelliğidir. Doğa, evrenin arkasındaki hayati ve motive güçtür” (Edgar ve Sedgwick, 2007, s. 241).

İnsanlar ekosistem içinde var olduklarında veya bir ekosisteme girdiklerinde, orada başat tür olmaya yatkınlık gösterir. Bu yüzden insanın başat olduğu ekosistemler diğerlerine göre daha kırılgandır (Bates, 2009, s. 91). Antropolojik açıdan insan âdetleri, girilen fiziksel çevreye uyarlanmalar olarak açıklandığından, koşullara göre ve çevreye uyum sağlamak amacıyla hızlıca değişebilen yaşam tarzları, kültür üzerine temellenen geniş bir esneklik alanı yaratır (Bates, 2009, s. 92). Dolayısıyla kültürü de bir ekolojik sistem olarak ele almak mümkündür. Kültürlerin ve ekosistemlerin en önemli sorunu "sürdürülebilirlik”tir. Her ne kadar kültürü sabit tutmak mümkün olmasa da ekosistemlerin sürdürülebilirliği için başlıca yol, içinde yaşayan canlılar için güvenli bir barınak olarak kalmasını sağlamaktır (Callenbach, 2011, s. 47).

Kentleşme ve sanayileşme gibi dinamiklerin etkisi başta olmak üzere, insanın doğaya hükmederek onu dönüştürmesi, günümüzde büyük bir ekolojik kriz ortaya çıkarmıştır. Kapitalizm ve buna bağlı sermayenin, ekosistemin bütünlüğünü bozarak adeta ekoloji-karşıtlığını kutsadığını belirten Joel Kovel, bu açıdan “üretim” olgusunun aslında doğayla ilgili olmadığını ve ekolojik krizin bu olguyla hızla yayıldığını aktarır (Kovel, 2017, s. 271): "Doğa hiçbir şey üretmez. Ekosistem adını verdiğimiz takımlar halinde birbirleriyle etkileşime giren yeni biçimler geliştirir, bunlar da evrimin sonraki aşamalarının yeri haline gelir. (...) O halde üretim, doğanın insani doğanın dolayımıyla ifade edilen biçimleyiciliğidir”. Ekoloji düşüncesi, üretim olgusu başta olmak üzere, modern dünyaya dair bilim, teknoloji ve ilerleme algılayışını değiştirecek bir şekilde "ekolojik aydınlanma"ya dönüşmüştür (Myerson, 2004, s. 3).

Ekoloji bilimi, zamanla insanların diğer canlılarla olan ilişkileri ile ekolojik süreçler üzerinde artan etkileri hakkındaki çalışmaları da kapsayarak yeni felsefi ve politik yak- 
laşımların ortaya çıkmasına neden olmuştur ve bu yaklaşımlar bilim olarak adlandırılmasalar da bazı bilimsel bulgulara dayanmaktadır (Callenbach, 2011, s. 42). Temel olarak insan ve doğanın geri kalanı arasındaki ilişkiyi merkeze alan bir felsefede birleşen ekoloji ve "yeşil" düşünceden, ekofeminizim, ekososyalizm, ekoanarşizm, ekokapitalizm ve ekofaşizm gibi sayısız siyasi ilke ortaya çıkmıştır (Wall, 2013, s. 59). Bu düşünce akımlarından derin ekoloji, toplumsal ekoloji ve ekofeminizm, ekolojik çalışmaları önemli ölçüde etkileyerek, oldukça zengin bir literatür ortaya çıkarmıştır.

İlk kez, 1973 yılında Arne Naess'in bir makalesinde kullanılan "derin ekoloji” kavram1, kendimiz ve doğaya ilişkin temel sezgi ve deneyimlerimizin birleştiği derin ve manevi bir ekoloji düşüncesiyle, ekolojik bilinci geliştirmeye yönelik bir çerçevede ele alınır (Devall ve Sessions, 2019, s. 136). Bu yüzden derin ekolojistler, ekolojik bilincin gelişimi için çeşitli filozoflar (Spinoza, Heidegger, vb.) ve dini geleneklerle (Zen Budizmi, Taoizm, vb.) ilgilenirler. Ancak derin ekolojistlerin, uzun vadede dünya nüfusunun azaltılması düşüncesi gibi bazı radikal fikirleri, eko-merkezci bu yaklaşımın insan düşmanı olduğu yönünde eleştiri almasına neden olmuştur (Garrard, 2016, s. 42-43).

“Toplumsal ekoloji” düşüncesinin en önemli düşünürü olan Murray Bookchin ise, ilkel doğa olarak adlandırdığı "birinci doğa"yı, insanın kültürel doğayı oluşturduğu "ikinci doğa"dan ayırır ve "toplum" dediğimiz kurumsallaşmış topluluk biçimi sayesinde "birinci doğa"nın, insan tarafından bilinçli bir şekilde değişikliğe uğradığını belirtir (Bookchin, 2019, s. 165). Bookchin gibi toplumsal ekolojistlerin temel amac1, günümüzdeki ekoloji karşıtı toplumun yerine, ekoloji yönelimli bir toplum yaratmaktır (Bookchin, 2019, s. 166). Bookchin, derin ekoloji başta olmak üzere diğer ekolojik düşüncelere oldukça tepki göstererek, toplumsal ekolojinin toplumsal ve akılcı perspektifle, doğal ve toplumsal fenomenlerin yarı-dini ve doğaüstü açıklamaları yerine, yanıtı evrim ve biyosferde arayan doğalcılığın tutarlı bir formuyla yetindiklerini aktarır (Bookchin, 2019, s. 163).

Bookchin'in bu "akılcı" yaklaşımını eleştiren ekofeminist Val Plumwood, toplumsal ekolojininin insan toplumundaki bazı hiyerarşi biçimlerine odaklanmasına rağmen hümanist, Aydınlanmac1, Hegelci ve Marksist geleneklerin pek çok sorunlu yönünü de miras aldığını belirtir (Plumwood, 2004, s. 29). Derin ekolojistlerle toplumsal ekolojistler arasındaki şiddetli "ekopolitika tartışması"nın çözümü için üçüncü bir yol olarak ortaya çıkan ekofeminizm, Batı kültüründe insan/doğa ilişkisinin ikicilik olarak görülmesini eleştirir ve bundan dolayı çevre krizinin temelinde, insan kimliğinin doğanın "dışında" 
kurgulanması düşüncesinin yattığını öne çıkarır (Plumwood, 2004, s. 10-11). Ekolojik feministler, Batı'da olumsuz bir kültürel değer yüklenen ve kadınların değersizleştirilip ezilmesinin temel nedenini oluşturan kadın-doğa bağlantısına olumlu bir değer yükleyerek, kadınların, kadınlığın ve doğanın statüsünü kültürel açıdan yeniden değerlendirmeye çalışır (Plumwood, 2004, s. 18). Dolayısıyla Plumwood gibi ekofeministlerin amacı, Batı'nın akıl ve doğa düşüncesinin gelişimi ve kusurlarını anlayarak ona tutsak olmamak ya da onun yeni bir versiyonuna tutulmamak için yol göstermektir (Plumwood, 2004, s. 15). Sonuç olarak, derin ekoloji, toplumsal ekoloji, ekofeminizm ya da diğer ekoloji perspektiflerinden pek çok kuramcı ve eleştirmenin yaklaşımları, ekoeleştirinin gelişmesini sağlamış ve kültürel çalışmalar için geniş bir kapı aralamışıtır.

\section{“Doğakültürel” İncelemelere Giriş Olarak Ekoeleştiri}

Temel olarak edebiyat ve fiziksel çevre arasındaki ilişki üzerine yoğunlaşan ekoeleştiri ya da çevreci eleştiri, insanın doğadaki en değerli varlık olması fikrine karşı doğal çevrenin ve diğer canlıların da hakları olduğu görüşünü öne çıkaran, "bir ayağı edebiyatta bir ayağı da doğada" konumlanan çevre çalışmalarıdır (Özdağ, 2017, s. 32). Yaşadığımız dünyayı eleştirel bir gözle incelemeyi amaçlayan ekoeleştiri, doğayla kültür arasındaki karmaşık süreç ve ürünlere eğilerek aslında "insan"1 eleştirel olarak inceler: "Ekoeleştiri en geniş tanımıyla, insanla insandışı arasındaki ilişkinin kültürel tarihi boyunca incelenmesi ve bizzat 'insan' kavramının eleştirel bir incelemesidir” (Garrard, 2016, s. 17).

1960'lı yıllarda temelleri atılan ekoeleştiri çalışmaları, özellikle 1980'lerde yükselişe geçmiş ve 1990'lı yıllarda çevre sorunlarının tüm dünyada görünür hale gelmesiyle bu dönemde kurumsallaşmaya başlamıştır (Özdağ, 2017, s. 35). Başlangıçta edebiyat merkezli başlayan ekoeleştiri çalışmaları, zamanla farklı disiplinlerde kültürel perspektifi olan diğer çalışmalara da esin kaynağı olmuştur. Ekoeleştiri çalışmaları, 80'lerden itibaren üç ana dalga halinde gelişmiştir: 1980'lerde çeşitli yazılarla başlayan birinci dalga, doğa adına konuşmayı amaçlamış; 1990'ların ortalarında başlayan ikinci dalga, toplum odaklı olarak kuramsal çalışmalara yönelmiş; günümüzde devam eden üçüncü dalga ise oldukça geniş bir çerçeveye yayılarak, küresel iklim değişikliği, biyoçeşitliliğin azalmas1, bölgesel ekosistemlerin tehdit edilmesi, çevre kirliliğine bağlı sağlık sorunları vb. konulara eğilmiştir (Özdağ, 2017, s. 38-41).

Ekoeleştirinin kültür odaklı olarak gelişmesi, doğa ve kültür konularının birlikte ele alınmasını gerektirmiştir. Çoğunlukla birbirinden farklı alanlar olarak düşünülen kültür ve 
doğa, ekoeleştiri (ve hayvan çalışmaları) açısından tümüyle "doğakültürel” olarak birbirine bağlıdır (Garrard, 2016, s. 270). Greg Garrard (2016) bu kavramı şu şekilde açıklar:

"Ekoeleştiri açısından yeniden ele alınmasının çok önemli olduğuna inandığım "insan" fikrini pastoral ve doğa yazınından uzaklaştırarak, küreselleşmeye ve doğayla kültürü birbirine karşıt kabul eden hakim ikiliği geçersiz kılan çok sayıdaki (Donna Haraway'in tanımıyla) “doğakültür”e yakın buluyorum” (s. 33).

Gerrard'ın feminist kuramcı Haraway'den aldığı "doğakültür" kavramı, ekolojik sorunların sadece bilimin konusu olarak değerlendirilmemesi gerektiğini, aynı zamanda kültürel incelemeye tabi tutulmasının önemini vurgular. Bu açıdan ekoeleştirmenler, çevre sorunlarının direkt çözümüne dair bilimsel bir öneri ortaya koymasa da doğa-kültür karşıtllı̆̆ yerine bu konuda ahlaki ve siyasi bir tavır alarak disiplinlerarası bir yönelimle edebiyat kuram1, kültür kuramı, felsefe, sosyoloji, psikoloji, çevre tarihi ve ekoloji alanlarının bilgi birikiminden yararlanırlar (Garrard, 2016, s. 31-32). Ancak ekoeleştirmenler, bir yandan “doğa”nın kültürel olarak inşa edildiğini, diğer yandan doğanın hem nesne hem de söylemin kökeni olarak gerçekten var olduğunu düşünürler. Bu yüzden dünyanın bilimsel olarak kavranmasını kabul etmelerine rağmen, bilimin nesnel ve toplumsal değerlerden azade olması fikrine uzak dururlar (Garrard, 2016, s. 24-25). Bu durum ekoeleştiriyi, kültürel çalışmalar açısından özel bir yere oturtur. Ekoeleştiri, insan bilimleri ile fen bilimlerinin diyaloğunu önemseyen disiplinlerarası tavrıyla, diğer kültürel çalışma alanlarına ve farklı bilim dallarına esin kaynağı olan, ama aynı zamanda onlardan beslenen bir yaklaşımdır (Özdağ, 2017, s. 43). Müzik araştırmaları ve müzikoloji disiplini de bunlardan birisidir. ${ }^{1}$

\section{Çevre/Doğa İlişkisi Bağlamında Ses, Gürültü ve Müzik}

Ses, gürültü ve müziğin ontolojik olarak tanımlanması ve bu kavramların doğadaki varoluşlarının belirlenmesi, her üçünün de birbirinin içine giren özellikler barındırmasından dolayı zorlaşabilmektedir. Doğal ya da doğal olmayan yollardan ortaya çıkan titreşimlerden oluşan sesler, titreşen bir nesnenin oluşturduğu ses dalgalarına dönüşerek, daha sonra kendi fiziksellikleri dışında "müzik" olarak kabul edilen toplumsal mutabakata bağlanırlar (Erol, 2009, s. 12). Yani seslerin müzik olarak kabulü, toplumdan topluma, kültürden kültüre değişkenlik gösterir. Çoğu zaman "yersiz ses" olarak tanımlanan ve istenmeyen, dikkat dağıtıcı, rahatsız edici bir şey olarak algılanan "gürültü" ile müzik

1 Ekoeleştiri ve popüler müzik ilişkisi üzerine örnek bir çalışma için bkz. Ingram (2010). 
arasındaki ilişkiyi ise geniş bir çerçevede ele alırsak, "yankıları, şarkı söylemeyi, davul vuruşlarını, çanları, gök gürültüsünü, silah seslerini, kalabalıkların gürültüsünü, insan bedeninden çıkan gurultuları, kahkahayı, sessizliği, kulak misafirliklerini, mekanik sesleri, gürültücü komşuları, müzikal kayıtları, radyoyu” kapsayacak şekilde, sesin ve dinlemenin her türünü bu ilişkiye dahil edebiliriz (Hendy, 2014, s. 12-13).

İnsanın sesle kurduğu ilişki hem onun çevre ve doğayla nasıl irtibat kurduğunu hem de onun müzik olarak tanımladığı şey(ler)in kültürel olarak nasıl anlamlandırıldığını gösterir. Dolayısıyla insan, doğayı sadece taklit etmeyip onu kendisine tabi kılmaya çalıştıkça, sesle neler yapılabileceğine dair oldukça geniş bir çeşitlilik ortaya çıkmıştır: Sesle dramatik efektler yaratmak, kozmostaki varlığımızı anlamımıza yardımcı olmak için sesi biçimlendirip kullanmak bunlardan bazılarıdır (Hendy, 2014, s. 43). Ancak müziği salt ses olarak, sesi ise sadece müzik üzerinden tanımlamak çok zordur. Müziği yalın sesten ayırmamızı sağlayan hem sesi hem de sesin duyulduğu dikkatli durumu içeren zamansal bir kılıf bulunur, yani müziğin varlığı zamanın içindedir. Dolayısıyla müziğin "maddeselliği”, ses ve zamanın birleşmesinden oluşur: "Müzik, zamanın sesi ve sesin zamanının bir sorgulamasıdır" (De Bolla, 2006, s. 66).

Sesin kültürel etkisi, bizi yarı bilinçli bir şekilde diğer canlı varlıklarla dolaysız bir ilişki içine sokmasından kaynaklıdır (Hendy, 2014, s. 306). Ancak müziği sadece insan tarafından üretilen ve kulağa hoş gelen sesler olarak ele almak, müziği sadece sesler olarak tanımlamak anlamına gelirken, onların taşıdığı iletileri dışlar. Bu yüzden Nicholas Cook, "müzik” kavramı için, rüzgar sesi ya da kuş cıvıltısı ile oratoryo veya şiir gibi “müziksel” nitelik taşıyan konuşmaları da dahil eden bir çerçeve önerir (Cook, 1999, s. 17). Çünkü müzik, kültürle ilişkili olduğu kadar doğayla da ilişkili olarak "doğal işitsel peyzaj” içinde gelişmiştir:

"Doğa ses aracılığıyla hem seyir sistemimiz hem saatimiz hem de takvimimizdir. Bize kılavuzluk eden onca teknolojiye sahip olduğumuz günümüzde zaman zaman bunu unutsak da geçmişte kendimizi sürekli doğal işitsel peyzaja göre ayarlamış olmalıyız. Çünkü uzak akrabalarımız için işitsel peyzaj son derece mühimdi, bu peyzaj dahilindeki her şey dikkatlerini çekiyordu. Onlara sadece en karanlık ormanlarda avlarını yakalamalarına yardımcı olmakla, tohumlarını ne zaman ekeceklerini göstermekle, hatta ruhlar âlemiyle iletişim kanalları sunmakla kalmadı. Yabanın sesleri atalarımızın yaptığı ilk müziği, söylediği ilk kelimeleri de belirledi. Çünkü insanların doğayla kurdukları ilişkinin en önemli özelliği onu taklit etmeleriydi" (Hendy, 2014, s. 40). 
Müzik algısının insanın “doğa”sında bulunup bulunmadığı ya da müziği algılamanın temelde bir alışkanlık olup olmadığı tartışması antikiteden beri devam eden bir meseledir (Fubini, 2006, s. 50). Ancak her durumda dinlemenin ve dolayısıyla kulakların kültürlenmesi gerçekleşmiştir (Fubini, 2006, s. 53). Toplumlar gelişip karmaşıklaştıkça müzik ve performans da karmaşıklaşıp uzmanlaşmış; birbirinden farklı etkileyici ses çıkarabilenlerle çıkaramayanlar birbirinden tamamen ayrılmıştır, yani icracılar ve dinleyiciler artık ikiye bölünmüş̧ür (Hendy, 2014, s. 59). Dolayısıyla müzik ve ses arasındaki ilişkiyi hem tarihsel hem de kültürel açıdan açıklamak mümkündür. Bu açıdan, Aaron Ridley (2004) müzik ve ses ilişkisini şöyle ele alır:

\footnotetext{
"Müziğin esas itibariyle ses-yapısı olduğunu varsaymak hatalıdır; onun doğru, gerçek, nihai doğasının yapılaşmış ses anlamında karakterize olduğunu düşünmek hatalıdır. (...) Müzik parçalarını örnek müzik kalıpları olarak değil, belki de dünyanın geri kalanının içindeki (şu veya bu dereceye kadar, ancak her zaman bir dereceye kadar) seslere ait kalıplar olarak ve onların tarihselliklerini de göz ardı etmeden ve anlamlarının da (en az yapının kültürün bir fonksiyonu olduğu kadar) kültürün bir fonksiyonu olduğunu gözden kaçırmadan ele almak zorundayız" (s. 24-25).
}

19. yüzyıldan itibaren sesin kaydedilmeye başlanması ve sesle ilgili teknolojilerin hızla gelişmesi, ses, müzik ve gürültü üzerine tartışmaları derinden sarsmış, yepyeni dinamikleri ortaya çıkarmıştır: Ses ve müziğin kaydedilmesi demek, sesin güdümlenebilmesi, tekrarlanabilmesi, çarpıtılması, hızlandırılması veya yavaşlatılması gibi çeşitli yöntemlerle duyurulabilmesi demektir (Hendy, 2014, s. 248). Bu bağlamda, kaynağı görülmeyen, kökeni saptanamayan veya yeri belirlenemeyen ses anlamına gelen "akuzmatik" kavramıyla ilişkili olarak, ayn "akuzmatik doğa"yı paylaşan radyo, gramofon, kasetçalar veya telefon gibi yeni araçların ortaya çımasıyla birlikte sesin akuzmatik niteliği evrenselleşmiş ve dolayısıyla sıradanlaşmıştır (Dolar, 2013, s. 64, s. 66). "Organik, doğal ve insan ölçeklerindeki gürültü”, endüstriyel gürültünün her şeyi tüketmesi karşısında ayakta kalmıştır; çünkü sesin teknoloji veya güçle değil, etikle yönetilmesi gerektiği daha da belirginleşmiş ve gündelik yaşamda mırıldanma, ıslık çalma veya konuşma eylemleri ile diğerlerinin bunları duyma imkanına sahip olması gereği öne çıkmıştır (Hendy, 2014, s. 255, s. 307).

Müziğin, ses, gürültü ve çevre/doğa ile ilişkisi, teknolojik gelişmelere paralel olarak hem müzikbilimciler hem de popüler müzik icracılarından çağdaş bestecilere kadar müzikle 
ilgili geniş bir kesim tarafından 20. yüzyıl ve sonrasında yoğun olarak ele alınmıştır. Kimi zaman müzik eserlerinin yazımında esin kaynağı, kimi zaman ise çevre duyarlılığı için aktivist bir çaba olarak karşımıza çıkan ve giderek gelişen bu çalışmalar, günümüzde ses merkezli "sonik sanat" çalışmalarını da etkilemiştir. Böylece ortaya çıkan bilimsel veya sanatsal eserlerle, "akustik ekoloji”leri bozulmuş "akustik ekosistem”leri dengeleyecek cevaplar üretilmeye çalışılmıştır.

Bu bağlamda, besteci R. Murray Schafer tarafindan 1960'lı yılların sonlarında ortaya atılan ve daha sonra bestecilikten etnomüzikolojiye kadar geniş bir çevrede kullanılmaya başlayan soundscape kavramı, sound (ses) ile landscape (manzara) kelimelerinin birleşiminden ortaya çıkmıştır: "Soundscape yalnızca bir ortamı, durumu ya da sesler bütününü değil, aynı zamanda belli bir sessel çevrenin, içinde yaşayanlarca nasıl algılandı̆̆ını tarif eder" (Özgün, 2018, s. 184). Schafer gibi besteci olan Barry Truax, akustik, psikoakustik, çevresel akustik ve gürültü ölçümü, elektro-akustik, müzik, dilbilim ve soundscape alanlarını birleştirerek "akustik ekoloji”nin çerçevesini genişletmiş; daha sonra "akustik iletişim" düşüncesiyle akustik ve işitsel deneyimleri anlamak için bir model önermiştir (Truax, 1978; 1984). Dolayısıyla bu yaklaşımlar, çevre-insan ilişkisinin ses yoluyla tanımlanması gerektiğine işaret eder. Schafer'le aynı dönemde yaşayan etnomüzikolog Steven Feld ise, acoustic (akustik) ve epistemology (epistemoloji) kelimelerinden türettiği acoustemology (akustemoloji) kavramı ile, "bilme ve dünyada olmanın bir yöntemi olarak sesin önceliğini araştırır” (Feld, 2003, s. 226). Müzik araştırmacıları, soundscape ve akustemoloji kavramlarını oldukça geniş bir şekilde ve zaman zaman farklı anlamlarda günümüze kadar kullanmışlardır (Özgün, 2018, s. 186-187).

Diğer yandan müzik araştırmaları, bu çalışmaları geliştiren ve çeşitlendiren pek çok yeni alana açılmıştır: Çevresel etnomüzikoloji, biyomüzikoloji, evrimsel müzikoloji, arkeomüzikoloji, hayvan müzikolojisi, ornitho müzikoloji vb. çeşitli yeni alanlarda, çevre/ doğa ilişkisi bağlamında ses, gürültü ve müzik konuları farklı açılardan incelenmiştir. Böylece, bugüne kadar doğanın, ortamların, ekosistemlerin sonik faaliyetlerinin gelişiminde ve ortaya çıtıktan sonra yorumlanmasında fazla bir rolü olmamakla eleştirilen müzikoloji disiplini, farklı alt dallarıyla bu meseleleri ele almaya başlamıştır (Keller, 2016, s. 170-171). Günümüzde "eski” müzikolojik paradigmaları sarsarak, yeni ya da eleştirel müzikoloji olarak adlandırılan çalışmalar, etnomüzikolojinin farklı alt dallarıyla da etkileşime girerek "yeni (etno)müzikolojiler" olarak değerlendirebileceğimiz geniş bir müzik bilimleri çerçevesi ortaya çıkarmıştır. 


\section{Eleştirel Müzikoloji ve Yeni (Etno)müzikolojiler}

İngiltere'de "eleştirel müzikoloji” ya da Amerika'da "yeni müzikoloji” olarak ortaya çıkan ve temel olarak 2. Dünya Savaşı sonrasında ortaya çıkan farklı eleştirel teorilerin etkisiyle gelişen çalışmalar, müzikolojinin temel paradigmalarına eleştirel gözle bakan bir perspektife sahiptir. ${ }^{2} 1960$ 'lı yılların sonlarından itibaren ilk örnekleri görülen ve 1980'li yıllarda hızla artan eleştirel ve yeni müzikoloji çalışmaları, müziğin bir bilim alanı olarak eleştirel açıdan ele alınması gerektiği yaklaşımıyla, 19. yüzyılın "salt müzik" (absolute music) düşüncesi gibi, müzikoloji alanında kabul edilen çeşitli teorilerle ilgili düşünsel bir paradigma değiş̧ikliği önerisi sunmuştur:

\footnotetext{
““'Yeni Müzikoloji’ müzikte bağlamsallığı ve temsili savunurken, müziğin kültürel ve tarihi bağlamdan ayrılabileceği fikrini reddeder. Kadın meselelerinin yanı sıra, etnomüzikoloji, siyahların müziği ve popüler müzik gibi önceden dışlanmış alanlara da kucak açar. Milliyetçilik, stil ve tür gibi geleneksel konulara ek olarak, sınıf, çağ, etnisite ve toplumsal cinsiyet farklılıkları gibi güçle ilgili konuları da içine alır. Yeni Müzikolojiyle bilimsel anlamda ilgilenmek, hem cinsiyetleştirilmiş bir sosyal düzen ürünü, hem de bir bildirisi olarak müzik hakkında eleştirel çalışmalar yapmayı, kadın müziklerinin yeniden önem kazanmasıyla ilgili çalışmaları, ayrıca hem kadın hem de erkeklerin bireysel eserlerindeki toplumsal cinsiyeti yorumlamanın -ya da ona direnmenin-, performativite, müzik üretimi ve icrası ve queer çalışmalar üzerindeki sosyal bağlam etkisinin, edinilen bilgeliğin, estetik değerleri yöneten standartların, yetenek ve zekâ kavramları ile kanon oluşum sürecinin eleştirel incelemesini kapsar" (Özkişi, 2013, s. 898).
}

Geleneksel müzikolojinin müziğe dar bir çerçevede odaklanması yerine, müziğin geniş anlamına dikkat çeken yeni müzikologların en karakteristik özelliği, çoğu zaman olası yorumların çokluğuna açık olmaları ve değer yargısından kaçınmalarıdır. Bu durum, otoritenin sorgulanması ve yalnızca farklı müzik alanlarındaki çabalara değil, aynı zamanda farklı müzikal yorumlama kaynaklarının değerine yönelik daha cömert bir tavır almalarından kaynaklanmaktadır (Cook ve Everest, 2001, s. 10). Edward T. Cone, Charles Rosen, Leo Treitler, Joseph Kerman, Anthony Newcomb, Carolyn Abbate ve Scott Burnham gibi erken dönemden itibaren eleştirel müzikoloji çalışmalarını sürdüren araştırmacılar hem müzikolojinin kendisine eleştiri yöneltmesi hem de eleştiri ve analiz

2 Eleştirel ve yeni müzikoloji çalışmaları üzerine çeşitli tartışmalar için bkz. Kerman (1985), Stock (1997), Hooper (2006). 
arasında bir denge kurarak, salt pozitivist yaklaşım yerine yorumlayıcı olması gerektiği ve teknik analizin tek başına değerlendirme yapmak için yetersiz kaldığı konusunda hemfikir olmuştur (Maus, 2010).

Akademik alanda yükselen postmodernizm ve postyapısalc1lı̆̆ın da etkisiyle, 1990’l1 yıllarda tüm dünyaya yayılan eleştirel ve yeni müzikoloji araştırmalarının, aslında gözden düşen eski müziksel düşünce paradigmalarının yerine daha geniş bir araştırma çerçevesi sunduğunu düşünen Derek Scott (2006), bu değişimi şu şekilde açıklar:

“1990'lardan beri ‘feminist müzikoloji’nin, ‘eleştirel müzikoloji'nin ve 'gey ve lezbiyen müzikoloji'nin yükselişi, alternatif müzikolojilerin varlığı yerine bir disiplin olarak müzikolojinin çöküşüne tanıklık ettiğimiz fikrini ortaya çıkarır. Muhtemelen birlikli bir disiplin kavramı, günümüzde gözden düşmüş bir müziksel düşünce paradigmasının parçasıdır. Bunun alternatifi, müzikolojiyi artık bir özerk akademik araştırma alanı değil, Fransız psikanalist ve göstergebilimci Julia Kristeva'nın deyişiyle, çeşitli anlamlama sistemlerinin yer değiştirme alanı olarak görmektir. Eleştirel müzikoloji, müzikolojiyi bir metinlerarası alan olarak görmenin ne anlama geldiğini ve neden bir disiplin nosyonundansa bunun, daha üretken bir araştırma çerçevesi sunduğunu gösterdi” (s. 168).

Diğer yandan, müzikoloji ve etnomüzikoloji disiplinleri arasında süregelen ayrım ve tartışmalara karşı, yeni ve eleştirel müzikoloji çalışmalarının da etkisiyle sayısız alt alan gelişerek hem kavramsal hem de yöntemsel olarak birbiriyle iç içe geçmiş "yeni (etno) müzikolojiler"in ortaya çıkmasına neden olmuştur. ${ }^{3}$ Yani, "artık hiçbir müzikal geleneği, müzik türünü ya da müzikle ilgili hiçbir ifadeyi dışlamayan bir perspektifle, çoklu müzik deneyimlerinin paylaşıldığı" bir çerçeve ortaya çıkmıştır (Yıldız, 2013, s. 28). Böylece müzik bilimi, tam da Scott’un günümüzdeki müzikolojiyi “metinlerarası bir alan” olarak tarif ettiği hale dönüşmüştür (Scott, 2006, s. 168).

Ancak bu yaklaşımlar, (etno)müzikologlar arasında her zaman aynı ilgi ve karşıllı̆̆ bulmamıştır: Örneğin etnomüzikolog Bruno Nettl, "yeni müzikoloji” olarak adlandırılan yönelimlerin, sözde “yeni” olduğu için bir yenilik iddia edemeyeceğini, ancak müziğin belirli sosyal teoriler çerçevesinde yorumlanmasını vurguladı̆̆ını aktarır (Yöre ve Nettl, 2012, s. 1194). Nettl, müzikoloji adına eklenen yeni, sosyo, eko vb. ekleri gereksiz eti-

3 Çeşitli müzikolog ve etnomüzikologların, "yeni” müzikoloji ve etnomüzikoloji araştırmaları ve deneyimleri üzerine tartışmalarını içeren, “yeni (etno)müzikolojiler” üzerine bir derleme için bkz. Stobart (2008). 
ketleme çabaları olarak görür ve bunların sadece kişisel ilgi alanları olduğunu düşünür (Yöre ve Nettl, 2012, s. 1197). Günümüzde, Nettl gibi bu “yeni” yönelimlere karşı çıkanlar olsa da yine Nettl'ın belirttiği gibi bunlar sayesinde (etno)müzikologların ilgi ve araştırma alanları oldukça genişlemiş; böylece "çoklu-müzikolojik" düşünme pratiği gelişmiştir (Yöre ve Nettl, 2012, s. 1198). ${ }^{4}$ Bu pratiklerden birisi de hem yeni (etno) müzikolojik yaklaşımlardan hem de ekoeleştirel düşünceden beslenen ekomüzikolojidir.

\section{Ekoeleştirel Müzikoloji Olarak Ekomüzikoloji}

Müzikolojide ekoeleştirel yaklaşım, özellikle 1970'li yıllarda Kuzey Amerika'da artan çevresel kaygının fizik, doğa ve sosyal bilimler alanlarına yayılmasına paralel olarak gelişmiş, ancak “ekomüzikoloji” olarak değer kazanması, 2000'li yıllarda Kuzey Amerika ve İskandinav akademik çevrelerinde gerçekleşmiştir (Allen, 2013). ${ }^{5}$ Diğer yandan yeni müzikoloji çalışmalarının pozitivist müzik araştırmalarına olan eleştirel ve aktivist yaklaşımı, ekomüzikolojiyi etkilemiş ve bu alanda çevre sorunlarına dikkat çeken eleştirel çalışmalar önemsenmiştir (Feisst, 2016, s. 2). Özellikle etnomüzikoloji ve tarihsel müzikoloji alanlarında çalışan araştırmacıların öncülük ettiği bu çalışmalara, 2007 yılında American Musicological Society tarafindan kurulan "Ecocriticism Study Group" ile 2011 y1lında Society for Ethnomusicology tarafindan kurulan "Ecomusicology Special Interest Group" adlı kurumsal yapılanmalar eklenmiş ve bu alandaki literatür gelişmiştir (Allen, 2013).

Ses araştırmaları, akustik, biyoakustik, sosyoloji, antropoloji, felsefe, kültürel çalışmalar ile çevre çalışmaları ve bilimleri gibi farklı alanlarla kesişen ekomüzikoloji çalışmaları, ilk zamanlarda çevresel değişim, küreselleşme ve Batı müzik endüstrisi tarafından tehdit edilen yerli müzik geleneklerinin sürdürülebilirliğine odaklanmıştır. Zamanla "derin ekoloji” düşüncesinden etkilenerek insan müziği ve insani olmayan sonik dünyalar arasındaki ilişkinin eleştirel incelenmesi, müzikal altyapıların ekosistemlerle karşılaştırılması, doğal kaynak kıtlığının çalgı yapımını nasıl etkilediğinin araştırılması, müzisyen-

4 Nitekim Nettl'ın "Mozart and the Ethnomusicological Study of Western Culture" başlıklı makalesi, müzikoloji alanı dışında ortaya çıkan ve müzikal analiz ile müzik eleştirisi gibi içeriden bakış açılarının tam zıttı bir metin olmasına rağmen, klasik müzik çalışmalarına güçlü alternatif perspektif sunmuş ve eleştirel müzikologlar tarafindan geniş çapta önemsenmiştir (Maus, 2010).

5 Ekomüzikoloji teriminin ilk kez 1972 yılında, R. Murray Schafer'in müzik, ekoloji ve soundscape çalışmaları üzerine düzenlenen bir tartışmada kullanıldığı düşünülmektedir (Allen, 2017, s. 94). Ayrıca 1964 tarihli daha erken bir makalede, "müziğin ekolojisi" kavramı müzik çalışmalarında ekolojik bir metafor olarak kullanılmış, ancak burada ekomüzikoloji veya çevre/doğa konularıyla ilgili herhangi bir referans verilmemiştir (Archer, 1964; Allen, 2017, s. 94). Ekomüzikoloji üzerine hazırlanmış en güncel ve kapsamlı çalışma için bkz. Allen ve Dawe (2016). 
lerin ve müzik medyasının karbon ayak izlerinin incelenmesi gibi çok çeşitli konularla ilgilenmiştir (Feisst, 2016, s. 2).

Ekomüzikoloji, müzikoloji ve etnomüzikoloji disiplinlerinin müzik ve kültür ilişkisini farklı açılardan ele alan çalışma konuları arasına doğayı da katarak, müzik, kültür ve doğa arasındaki bağlantıları ortaya çıkarmayı hedefler (Allen, 2017, s. 92). Müzik doğaya açıldığında, çevredeki tüm seslerin akışını (müzik dahil) düşünürek, birçok yönden avantajlı bir bakış açısı ortaya çıkarır: "Ses, mekanı kutsal bir yere dönüştürür; insanları da kapsayarak hayvanlar arasında iletişimi sağlar; ve varlıkların birbirleriyle ve çevreleriyle bir arada yaşamalarını sağlar. Şüphesiz sesin tınlaması sadece evrimsel bir avantaj değil, aynı zamanda dünyadaki yaşamı sürdürmek için bir gerekliliktir" (Titon, 2013, s. 17). Diğer yandan ekomüzikologlar, bu bağlantıları ortaya koyarken müzikle ilgili eleştirel yönelimi koruyarak, ekoeleştirel ve doğakültürel bir yaklaşımla çevre krizinin kültürel köklerini anlamada ve değişimi teşvik etmede katkıda bulunurlar (Allen, 2016, s. 647).

Philip Bholman'ın, herhangi bir müzikoloji çalışmasında neyin araştırılmak üzere seçildiği ve neyin dışlandığına göre bunun aslında politik bir eylem olduğu görüşlerinden yola çıkan Aaron Allen, yirminci yüzyılın büyük bir bölümünde müzikolojinin apolitik konumunda 1srar ettiğini ve kendi siyasi eylemleriyle yüz yüze geldiğini belirterek, müzikologların görmezden geldiği "diğerleri” arasına, dünyanın kendisini de dahil etmemiz gerektiğini vurgular (Allen, Titon ve Glahan, 2014, s. 3). Ekomüzikolojinin kavramsal ve yöntemsel gelişimi konusunda önemli çalışmaları bulunan Allen, doğa, çevresel kriz ve müzikoloji ilişkisi üzerine aşağıdaki önemli sorulara cevap arayarak, müzikoloji çalışmaları ile ekoeleştiri arasında sıkı bir bağlantı kurar:

\footnotetext{
“- Müzikoloji, sorunun mu yoksa çözümün mü bir parçasıdır?

- Müzikoloji insanlığın refahında ve hayatta kalmasında nasıl bir rol oynar?

- Doğa müziği nasıl bilgilendirir ve müzik çalışması bize insanlar, diğer türler, yapılı çevre, doğal dünya, yapılı “doğa” ve onların bağlantıları hakkında neler anlatabilir?

- Müzikoloji bizi yeryüzündeki yaşama daha iyi adapte ediyor mu, yoksa bazen yaşamdan kurtariyor mu?

- Hayatta kalmamıza, neslimizin tükenmesinden daha fazla katkıda bulunuyor mu?

- Çevresel kriz müzikle alakalı mı ve daha da önemlisi müzikoloji bunu çözme ile alakalı mi?" (Allen, 2011, s. 392).
} 
Bu sorulara verilecek cevaplar, ekomüzikologların çalışma sahalarıyla kurdukları ilişkide konumlanmaları açısından çok önemlidir. Self-reflexive (özdüşünümsel) bakış açısını da yansıtan bu konumlanma, eleştirel düşünce ile yeni müzikolojinin bir araya geldiği bir perspektif sunar. Dolayısıyla ekomüzikoloji, tıpkı müzikoloji gibi politik bir eylemdir, ancak sonuçları sadece müzik disipliniyle ilgili değildir (Allen, Titon ve Glahan, 2014, s. 3). Bu açıdan Allen, ekomüzikolojiyi bir disiplin yerine bir "alan" olarak tanımlar ve sosyal bilimlerden doğa bilimlerine kadar birçok disiplinin birlikte çalışabileceği bir çerçeve önerir: ${ }^{6}$

"Ekomüzikoloji, daha katı bir disiplin olmaktan ziyade, çevre çalışmaları ve sürdürülebilirlik gibi birçok disiplinin bir araya geldiği, sadece müzik ve sese ilgi duyan bir alandır. Ekoloji, antropoloji, coğrafya, çevre tarihi ve edebi ekoeleştiriye dayanan ekomüzikoloji, müzikolojinin bir alt alanıdır. Şimdi, müzikoloji bazen belirsiz bir disiplin olarak görülüyor, çünkü ses ile müziğin, performans veya kompozisyonuyla ayrı olmaktan ziyade birlikte ele alınmasıdır. Bilimsel-çevresel çalışmaların, kültürel-müzik çalışmaları ile birlikte ele alınmasında ekomüzikoloji gerçekten disiplinlerarası bir alandır" (Allen, Titon ve Glahan, 2014, s. 6-7).

Ekomüzikoloji, çalışma konuları ve metodoloji açısından sürekli yenilenen bir yaklaşım olarak, çalışma alanına ilgi düzeyi ve güncelliğini, aciliyet duygusu ile farkındalık yaratma, uygulama ve aktivizmden alarak genel müzikoloji pratiğinden ayrılır (Rehding, 2011, s. 410). Çevre ile ilgili endişeleri temel olarak iki kampa ayıran Alexander Rehding (2011), ilk grupta belirgin bir akut kriz duygusu ile alarmcı ve distopik "kıyamet" düşüncesinin, ikinci grupta ise geçmişe romantik bir özlemle ütopik ve kültürel hafızaya dayanan "nostalji” duygusunun ağır bastığını belirtir (s. 409-410, s. 414). Anlatı sanatlarında genel olarak kıyamet düşüncesi işlense de belleğin gücüne hitap etmek konusunda müziğin üstün bir alan olduğunu düşünen Rehding, çevre hareketinin çekiciliğinin her zaman büyük bir parçası olan nostaljik hayal gücünün müziğe daha uygun olabileceğini aktarir (Rehding, 2011, s. 412, s. 414).

Bazı ekomüzikologlar, idealize edilmiş doğanın cazip temsillerini ve doğaya insanın yansımasını temsil eden müzik eserlerini (örneğin Beethoven'ın 6. "pastoral” senfonisi) eleştirel açıdan incelerken (Allen, Titon ve Glahan, 2014, s. 3); bir kısım ekomüzikolog-

6 Allen'ın bu perspektifi, akademide genel olarak studies (çalışmalar) olarak tanımlanan ve özellikle "kültürel çalışmalar” için önemli bir çerçeve oluşturan yaklaşıma da uygundur: “"Çalışmalar' başlı başına bir öğreti bütünü oluşturmaz, disiplinlerin bir araya gelmesidir. Disiplinden çok, bir nesne çevresinde oluşan bilgi alanlarıdır. Bunun temel etkisi, yalnızca kullanılan ve üretilen kavramların çokdisiplinli bakış açısıyla tartışılmasının ve dönem dönem yeniden tanımlanmasının sağlanması değil, aynı zamanda bilgilerin ayrımlanmasının yerindeliğinin sorgulanmasıdır" (Bourse ve Yücel, 2017, s. 10). 
lar müziğin ekopolitik etkilerine ve ekolojik farkındalığı teşvik etmek amacıyla çevresel aktivizme kendini adamış (örneğin popüler müzik yapan) müzisyenlere eğilerek müzikle ilgili geniş bir alanda çalışırlar (Feisst, 2016, s. 2). Dolayısıyla ekomüzikologlar, araştırmanın ihtiyacına göre eserlerin yorumlanması için eleştirel analiz ya da etnografik alan çalışması gibi farklı araştırma yöntemlerini kullanabilirler. Yani Allen'n yukarıda bahsettiği gibi, ekomüzikologlar birçok disiplinin birlikte çalışabileceği farklı kavramsal ve yöntemsel araçlardan yararlanabilir. Bu yüzden Allen, “ekomüzikoloji”nin “müzikoloji”sini, Charles Seeger'ın “bütüncül müzikoloji” önerisine uygun olarak, bugünün tarihsel müzikoloji, etnomüzikoloji ve diğer ilgili disiplinlerarası alanlarını kapsayan örtük bir şemsiye olarak görür ve bunun ekolojik eleştirel müzik çalışmalarında farklı disiplinleri bir araya getirme açısından oldukça fayda sağlayacağını düşünür (Allen, 2013). ${ }^{7}$

Ekomüzikoloji bağlamında bir başka örnek çalışma olarak, rock ve folk müzisyenlere odaklanan Mark Pedelty, müziği bir çevre iletişimi, ekolojik sanat ve savunuculuk biçimi olarak ele alır. Bu müzisyenler arasında uzun süreli ekomüzikolojik alan çalışması yapan Pedelty, çevresel konulara aracılık olarak, çevresel anlamların yaratıcı, estetik, sembolik, duygusal ifadesi olarak ve dinleyicileri bilgilendirme, ilham verme, ikna etme girişimi olarak müziğin işlevine odaklanır. Pedelty çalışmasında, ekoeleştiri, klasik müzikoloji, biyolojik ekoloji, etnomüzikoloji ve çevre iletişiminden yararlansa da çevresel sorunlara uygulandığında bu alanların toplu olarak kabul gördüğü disiplinlerarası alanın "ekomüzikoloji” olduğunu vurgular ve kitabına bu başlığı verir (Pedelty, 2012, s. 7).

Uygulamalı (etno)müzikoloji çalışmalarıyla yakın temasta olan bazı ekomüzikologlar ise müzik kültürlerinin birer ekosistem olarak sürdürülebilirliği için çalışmaktadır. Buna göre müzik kültürleri, sosyal ve ekolojiktir (Titon, 2009, s. 122). Bu konuda çalışan Huib Schippers (2015), “müzikal ekosistemler” olarak tarif ettiği müzik kültürlerinin sürdürülebilirliğini ele almak için, "beş alanlı ekosistemler" adını verdiği şu beş konu üzerine odaklanılması gerektiğini önerir:

“1) Müziğin aktarılıp sürdürülebilmesi için müzik öğrenme sistemlerini değerlendirmek.

2) Müzisyenlerin topluluklarındaki konumlarını, rollerini ve etkileşimlerini ve bu bağlamda geleneklerinin sosyal temellerini incelemek.

7 Bu konuda bir şerh düşen Marcello Sorce Keller, bu kadar geniş bir çağdaş müzikoloji yelpazesinin hem heyecan verici hem de kafa karıştırıcı olabildiğini; daha fazla alan belirlendikçe, birbirlerini daha fazla görmezden gelme eğiliminin artabileceğini ve örneğin etnomüzikolojinin artık 1970’lerdeki kadar kapsamlı bir alan olarak görünmediğini belirtir (Keller, 2016, s. 172). Bu açıdan Allen’ın bütüncül yaklaşımının önemli olduğu söylenebilir. 
3) Müzikal geleneklerin sosyal ve kültürel bağlamlarını değerlendirerek hem müzik uygulamalarının düzenini hem de bunların altında yatan değerleri ve tutumları (yapıları) incelemek. 4) Müziğin hayatta kalabilmesi için esas olan, üretme, yapma, uygulama ve öğrenme mekanları ile yaratma, işbirliği, öğrenme, arşivleme ve yayma için sanal alanların altyapısını oluşturmak.

5) Sürekli değişen müzik dağıtma, yayınlama ve destekleme biçimlerini, izleyicilerin, müşterilerin, sponsorların, fon veren kuruluşların ve devletlerin, bunları sanatsal ürün olarak 'satın alma' veya 'alışverişini yapma' rollerini göz önünde bulundurarak incelemek” (s. 145).

Ancak burada temel mesele, müzik kültürüne ekosistem olarak yaklaşan (etno)müzikoloğun, neyi ne kadar koruyabileceği veya etkileyebileceği konusudur. Schippers'a göre sayısız dış etki giderek artan bir şekilde neredeyse tüm müzik uygulamalarının ayrılmaz bir parçasını oluşturduğundan, müziği etkileyen tüm güçleri -teknoloji, ticarileşme, yasama, küreselleşme ve medya dahil- ekosistemin bir parçası olarak olarak görmek daha doğru ve verimli olabilir (Schippers, 2015, s. 144). Bu açıdan Schippers, bütüncül bir perspektif önerir. Nitekim bu çalışmalarda, müzik, ses ve ses üreten çalgılara dair düşünceler, kayıt stüdyoları, medya, salonlar, müzik eğitimi ve yayıncılık, kültürel üretim ve kültürel alan olarak (müzikal bireyler, nüfuslar ve toplulukların sağlığını da ilgilendiren) müzik ekonomisi gibi “müzikal çevre”nin tüm fiziksel ve kültürel faktörleri “müzikal habitat"1n birer parçası olarak kabul edilir (Titon, 2009, s. 122).

Sonuçta ekomüzikoloji, sadece “doğa” ile ne kastettiğimizi değil, aynı zamanda "müzik" ile ne kastettiğimizi de eleştirel bir incelemeye tutarak, tartışılan nesnelere genişleyen bir bakış açısıyla yaklaşmayı ve bunların cevabını ortaya çıkarmayı hedefleyen bir yönelime sahiptir (Rehding, 2011, s. 412). Yani ekomüzikoloji, ekoeleştirel ve doğakültürel bir müzikoloji yaklaşımı olarak, müzik, kültür ve doğa ilişkisi üzerine eleştirel sorular yönelten ve bunların cevabını arayan disiplinlerarası bir alandır.

\section{Sonuç}

İnsan ve doğa ilişkisi, günümüzde eleştirel olarak yeniden ele alınmaktadır. Özellikle Batı kültüründe insan ve doğanın karşıtlık olarak kurgulandığı düşünce biçimi, eleştirel çalışmalarla derinlemesine incelenmiş ve eleştirilmiştir. 2. Dünya Savaşı sonrasında hem akademik alanda eleştirel düşüncenin gelişmesi hem de tüm dünyada yaşanan çevresel krizlerin görünür hale gelmeye başlamasıyla, çevre/doğa bilinci üzerine tartışmalar artmıştır. 1960'lı yılların sonralarından itibaren farklı bilim alanlarında eleştirel yaklaşım- 
lar çoğalmaya başlamış, zamanla postmodernizm ve postyapısalcılık tartışmalarıyla bunlar daha da ön plana çıkmıştır. Edebiyat alanında ekoleştiri düşüncesinin gelişmesine paralel olarak, müzikoloji alanında eleştirel veya yeni müzikoloji çalışmaları ile mevcut paradigmalar sarsılmış, bu bağlamda müziğin ne olduğu sorusu oldukça geniş bir çerçeveden ele alınmaya başlamıştır.

İnsan-doğa ilişkisinin yeniden ele alındığı bu dönemde, bir yandan akademik çalışmalar, diğer yandan çevre için aktivist faaliyetler artmış, doğal yaşamın korunmasından çevre krizine kadar pek çok konuda bilimsel, sanatsal veya aktivist çalışmalar yürütülmüştür. $\mathrm{Bu}$ çalışmalar içinde ekosistemlerin sürdürülebilirliği en önemli başlıklardan birisidir. $\mathrm{Bu}$ çalışmaların müzikolojiye yansıması da benzer dönemlerde olmuştur. Ekoeleştirel düşünce ile müzikolojinin bir araya geldiği ekomüzikoloji alanı, müzik ve kültür çalışmalarına doğayı da dahil ederek hem çalışma sahasını oldukça genişletmiş hem de doğada var olan her tür sese dair yeni çalışmalar yürütülmesine olanak sağlamıştır. Kavramsal ve yöntemsel olarak müzikoloji ve etnomüzikoloji disiplinleriyle iç içe olduğu kadar diğer disiplinlere de açık olan ekomüzikologlar, disiplinlerarası bir yönelime sahiptir. Çevre/doğa konularında politik konumlanmalarıyla hem akademide hem de akademi d1şında çevre/doğa bilincini geliştirip ekolojik krizlere müzik araştırmaları yoluyla cevap arayan ekomüzikologlar, bu yüzden buldukları cevaplarla müzikolojinin bir adım ötesine geçerek, çevre/doğa konularına "müdahil”" olmaktadır.

Çalışma konuları, kavramsal dünyası ve yöntemsel araçları oldukça çeşitli olan ekomüzikoloji, ekoeleştirel ve doğakültürel bir müzikoloji yaklaşımı olarak hızla gelişen bir alandır. Ülkemizde çevre/doğa konusundaki çeşitliliği ve son yıllardaki duyarlılığı göz önünde bulundurursak, gelecekte Türkiye'de ekomüzikoloji alanında yapılacak çalışmalarla, müzik, kültür ve doğa ilişkisi üzerine çok zengin bir literatür ortaya çıkacaktır.

Finansal Destek: Yazar bu çalışma için finansal destek almamıştır.

\section{Kaynakça}

Allen, A. S. (2011). Ecomusicology: Ecocriticism and musicology. Journal of the American Musicological Society, 64(2), 391-394.

Allen, A. S. (2013). Ecomusicology. Grove Music Online. Retrieved 12 June 2019, from https://www.oxfordmusiconline.com/grovemusic/view/10.1093/gmo/9781561592630.001.0001/omo-9781561592630-e-1002240765

Allen, A. S. (2016). Ecomusicology between poetic and practical. In H. Zapf (Ed.), Handbook of ecocriticism and cultural ecology (pp. 644-663). Berlin: De Gruyter. 
Allen, A. S. (2017). Greening the curriculum: Beyond a short music history in ecomusicology, Journal of Music History Pedagogy, 8(1), 91-109.

Allen, A. S. ve Dawe, K. (Eds.). (2016). Current directions in ecomusicology: Music, culture, nature. New York: Routledge.

Allen, A., Titon, J. T. ve Glahn, D. V. (2014). Sustainability and sound: Ecomusicology inside and outside the academy. Music \& Politics, 8(2), 1-26.

Archer, W. K. (1964). On the ecology of music. Ethnomusicology, 8(1), 28-33.

Bates, D. G. (2009). 21. yüzyılda kültürel antropoloji: İnsanın doğadaki yeri (S. Aydın vd., Çev.). İstanbul: İstanbul Bilgi Üniversitesi Yayınları.

Bookchin, M. (2019). Derin ekolojiye karşı toplumsal ekoloji (E. Günok, Çev.). Cogito, 93, 147-166.

Bourse, M. ve Yücel, H. (2017). Kültürel çalışmaları anlamak (H. Yücel, Çev.). İstanbul: İletişim Yayınları.

Callenbach, E. (2011). Ekoloji: cep rehberi (E. Özkan, Çev.). İstanbul: Sinek Sekiz Yayınevi.

Cook, N. (1999). Müziğin ABC’si. (T. Doğan, Çev.). İstanbul : Kabalcı Yayınevi.

Cook, N. ve Everest, M. (2001). Preface. In N. Cook \& M. Everest (Eds.), Rethinking music (pp. v-xii). New York: Oxford University Press.

De Bolla, P. (2005). Sanat ve estetik (K. Koç, Çev.). İstanbul: Ayrıntı Yayınları.

Devall, B. ve Sessions, G. (2019). Derin ekoloji (E. Günok, Çev.). Cogito, 93, 136-146.

Dolar, M. (2013). Sahibinin sesi: Psikanaliz ve ses (B. E. Aksoy, Çev.). İstanbul: Metis Yayınları.

Edgar, A. ve Sedgwick, P. (Ed.). (2007). Kültürel kuramda anahtar kavramlar (M. Karaşahan, Çev.). İstanbul: Açı$\lim$ Kitap.

Erol, A. (2009). Müzik üzerine düşünmek. İstanbul: Bağlam Yayınları.

Feld, S. (2003). A rainforest acoustemology. In M. Bull \& L. Back (Eds), The Auditory Culture Reader (pp. 223-39). Oxford: Berg Publishers.

Feisst, S. (2016). Music and ecology. Contemporary Music Review, 35(3), 1-3.

Fubini, E. (2006). Müzikte estetik (F. Genç, Çev.). Ankara: Dost Kitabevi Yayınları.

Garrard, G. (2016). Ekoeleştiri: Ekoloji ve çevre üzerine kültürel tartışmalar (E. Genç, Çev.). İstanbul: Kolektif Kitap.

Hendy, D. (2014). Gütültü: Sesin beşeri tarihi (Ç. Çidamlı, Çev.). İstanbul: Kolektif Kitap.

Hooper, G. (2006). The discourse of musicology. Aldershot: Ashgate Publishing.

Ingram, D. (2010). The jukebox in the garden: Ecocriticism and American popular music since 1960. Amsterdam: Rodopi.

Keller, M. S. (2016). Linnaeus, zoomusicology, ecomusicology, and the quest for meaningful categories. Musicological Annual, 52(2), 163-176.

Kerman, J. (1985). Contemplating music: Challenges musicology. Cambridge, Massachusetts: Harvard University Press.

Kovel, J. (2017). Doğanın düşmanı: Kapitalizmin sonu mu, dünyanın sonu mu? (G. Koca, Çev.). İstanbul: Metis Yayınlar1.

Maus, F. E. (2010). What was critical musicology? Radical Musicology. 10. Retrieved 12 June 2019, from http:// www.radical-musicology.org.uk/special_critmus/maus.htm 
Myerson, G. (2004). Ekoloji ve postmodernliğin sonu (E. Kılıç, Çev.). İstanbul: Everest Yayınları.

Özdağ, U. (2017). Çevreci eleştiriye giriş: Doğa, kültür, edebiyat. Ankara: Ürün Yayınları.

Özgün, E. Ş. (2018.) Soundscape çalışmalarına etnomüzikolojiden bir bakış. MSGSÜ Sosyal Bilimler Dergisi, 2(17), $182-191$.

Özkişi, G. Z. (2013). Müzik disiplini bağlamında feminist müzik teorisi ve cinsiyet semantiği. Turkish Studies, 8(12), 889-961.

Pedelty, M. 2012. Ecomusicology: Rock, folk, and the environment. Philadelphia: Temple University Press.

Plumwood, V. (2004). Feminizm ve doğaya hükmetmek (B. Ertür, Çev.). İstanbul: Metis Yayınları.

Rehding, A. (2011). Ecomusicology between apocalypse and nostalgia. Journal of the American Musicological Society, 64(2), 409-414.

Ridley, A. (2004). Müzik felsefesi: tema ve varyasyonlar (B. Aydın, Çev.). Ankara: Dost Kitabevi Yayınları.

Schippers, H. (2015). Applied ethnomusicology and intangible cultural heritage: Understanding "ecosystems" of music as a tool for sustainability. In S. Pettan \& J. T. Titon (Eds.), The Oxford Handbook of Applied Ethnomusicology (pp. 134-157). New York: Oxford University Press.

Scott, D. B. (2006). Postmodernizm ve müzik (M. Erkan ve A. Utku, Çev.). S. Sim (Ed.), Postmodern düşüncenin eleştirel sözlüğü kitabı içinde (s. 157-170). Ankara: Ebabil Yayınları.

Stobart, H. (ed.). 2008. The new (ethno)musicologies. Maryland: Scarecrow Press.

Stock, J. P. J. (1997). New musicologies, old musicologies: Ethnomusicology and the study of Western music. Current Musicology, 62, 40-68.

Titon, J. T. (2009). Music and sustainability: An ecological viewpoint. The World of Music, 51(1), 119-137.

Titon, J. T. (2013). The nature of ecomusicology. Music E Cultura, 8(1), 8-18.

Truax, B. (1978). Handbook for acoustic ecology. Vancouver: ARC Publications.

Truax, B. (1984). Acoustic communication. New Jersey: Ablex Publishing.

Yıldız, B. (2013). Etnomüzikoloji’de tarihsel yaklaşımlar ve yöntem tartışmaları: "Yeni”" alan araştırmaları ve “yeni” (etno) müzikoloji. A. Öztürkmen (Haz.), Müzik, dans, gösterim: Tarihsel ve kuramsal tartışmalar kitab1 içinde (s. 9-32). İstanbul: Boğaziçi Üniversitesi Matbaası.

Yöre, S. ve Nettl, B. (2012). Bruno Nettl ile etnomüzikolojik değerlendirmeler. International Journal of Human Sciences. 9(2), 1189-1205.

Wall, D. (2013). Yeşil politika (İ. E. Kelso, Çev.). İstanbul: Yeni İnsan Yayınevi.

Williams, R. (2012). Anahtar sözcükler: Kültür ve toplumun sözvarlı̆̆ı (S. Kılıç, Çev.). İstanbul: İletişim Yayınları. 
